\title{
Ensinando ciências numa perspectiva histórico-filosófica
}

\author{
Teaching sciences in a historical-phylosophic perspective \\ Dalana Campos Muscardi \\ Débora Schmitt Kavalek
}

\begin{abstract}
Resumo: A História da Ciência é frequentemente negligenciada nos cursos de formação de professores e também nos conteúdos expostos nos livros didáticos. Contudo, quando presente, muitas vezes possui um caráter ilustrativo, não sendo explorada devidamente pelas (os) docentes. $\mathrm{O}$ ensino a partir da História da Ciência promove uma abordagem contextualizada com a natureza do conhecimento científico, permitindo aos professores explorar os aspectos culturais, sociais, econômicos, políticos e filosóficos presentes no período da construção de um conhecimento. Dessa forma, é possível desconstruir a visão neutra e acumulativa da ciência, do gênio, da descoberta e da imparcialidade dos cientistas. Além disso, a adoção do ensino de ciências numa perspectiva históricofilosófica enquanto prática pedagógica na sala de aula, permite a abordagem sistêmica do conteúdo, relacionando ciência-tecnologia-sociedade-ambiente, contribuindo para uma efetiva alfabetização científica do estudante, empoderando-o como um cidadão crítico e ativo em sua realidade. Este trabalho apresenta uma proposta de minicurso que teve como objetivo debater a importância do ensino numa abordagem histórico-filosófica e apresentar propostas para a inserção da história da ciência no ensino de ciências, numa perspectiva interdisciplinar. A formação destinou-se a professores de ciências dos anos finais do ensino fundamental e contou com uma parte teórica, relacionada ao ensino histórico de ciências e uma parte prática, que apontou sugestões para inserir a história da ciência durante as aulas.
\end{abstract}

Palavras-chave: história e filosofia da ciência; formação de professores; ensino de ciências.

Abstract: The History of Science is often neglected in teacher training courses and also in the textbooks contents. However, when it is present, it is often illustrative and are not properly explored by teachers. The History of Science teaching aproach promotes the knowledge of the nature of scientific knowledge by students, and allow teachers to explore the cultural, social, economic, political and philosophical aspects present in the construction of the knowledge. In this way, it is possible to deconstruct the neutral and cumulative view of the science, the genius, the discovery, and the scientists impartiality. In addition, the adoption of the historical-philosophical approach of science teaching as a pedagogical practice in the classroom, allows a systemic approach to content, relating science-technology-society-environment, contributing to the effective students's scientific literacy, empowering them as critical and active citizens in their realities. This paper presents a brieth discussion of the importance of teaching in a historicalphilosophical approach, obtained from the effects off a short course on teacher's conceptions about this approach. The course had a theoretical part related to science teaching in a historical perspective, and a practical part which proposed suggestions for inserting the history of science during the classes.

Keywords: science history and phylosophy; teacher training; sciences teaching.

\section{Introdução}


Há muitas razões pelas quais o estudo da história e da filosofia da ciência deve fazer parte de programas de formação de professores de ciências. O ensino contextual, a partir da história da ciência, (PRESTES e CALDEIRA, 2009) pode auxiliar $\mathrm{a}(\mathrm{o})$ docente em relação às dificuldades de aprendizagem dos alunos, pois alerta-os para as dificuldades históricas do desenvolvimento científico e conceitual da ciência. Segundo as ideias de Matthews (1988), através dos estudos históricos, os professores desafiam as(os) educandos a identificar os avanços, erros, contextos econômicos, históricos, sociais e as dificuldades conceituais que envolveram a ciência. Outra contribuição da história da ciência é conduzir a uma educação científica multicultural, envolvendo a ciência feminista, a falibilidade da ciência, o impacto da política e interesses especiais como questões raciais e interesses de classe, a ciência ambiental, a aprendizagem de pesquisa, a abordagem ciência-tecnologia-sociedade, a preocupação com a natureza do conhecimento humano e sua produção e validação, auxiliando na estruturação de um currículo preocupado com a humanização da ciência.

Segundo Chassot (2007a, p. 113),

a ciência é uma das mais extraordinárias criações do homem, que the confere, ao mesmo tempo, poderes e satisfação intelectual, até pela estética que suas explicações lhe proporcionam. No entanto, ela não é lugar de certezas absolutas e [...] nossos conhecimentos científicos são necessariamente parciais e relativos.

Chassot (2008), defende que o(a) educador (a) deve levar o educando a ser um cuidador do mundo, usando a ciência como instrumento para promover o bem-estar social por meio da alfabetização científica. O conceito de alfabetização científica, para Chassot (2006), é entender Ciências como se fosse uma linguagem que é escrita e falada, construída e compreendida ao longo dos tempos, e que se dá pela relação entre os comunicantes. A alfabetização científica, segundo o autor, também permite a possibilidade de poder entender e manusear a ciência, conhecendo seus limites e responsabilidades.

Contraditoriamente, muitos acreditam na ciência como uma verdade absoluta, imutável, elaborada por gênios, masculina, branca e europeia, sem relação com o contexto social, econômico, religioso e político. Na prática, 
muitas (os) docentes desconhecem fatos históricos e verídicos que influenciaram a construção do conhecimento científico disseminando, muitas vezes, lendas, imprecisões, inverdades e fatos distorcidos da história da ciência. Tal aspecto termina por conduzir a um ensino neutro, descontextualizado, hierárquico e acrítico.

A maioria dos fatos históricos "escolhidos" para compor, principalmente os livros didáticos, respeitou pouquíssimo o contexto histórico dos documentos, tomando ciências recentes como parâmetros para verificar supostos fracassos em evoluções de ciências anteriores. Como se sabe, derivaram daí, em grande parte, os anacronismos verificados no ensino das ciências, de acordo com Alfonso-Goldfarb (2008).

Com o passar do tempo, como acontece em várias outras áreas, os métodos de abordagem em história da ciência vêm mudando. Existem várias maneiras pelas quais a integração da história e filosofia da ciência na escola é possível: seleção e leitura de fontes originais; projetos conjuntos com outros componentes curriculares como história, literatura e artes; dramatizações de episódios significativos na história da ciência; e até mesmo debates sobre assuntos atuais. Toda filosofia da ciência começa com questões analíticas e lógicas como, por exemplo: O que significa um conceito específico? O que é uma teoria? Como sabemos a verdade de uma proposição? Essas questões analíticas e lógicas podem ser introduzidas já na pré-escola (LIPMAN, 1995), quando discutimos a linguagem que usamos para debater e entender a natureza, envolvendo os "três Ps" da ciência: problematização, solução de problemas e persuasão de pares.

A História da Ciência no ensino não envolve apenas a história dos fatos científicos, mas também a de outras questões éticas envolvendo noções como justiça, igualdade, distribuição justa de bens, responsabilidade e afins, que podem ser esclarecidas pela análise filosófica e por referência à história dessas questões. De acordo com Rubba et al. (1991), temas como: espécies em extinção, engenharia genética, transplantes de órgãos, guerra nuclear, exploração espacial, gestão de resíduos, poluição, energia e outros, discutidos superficialmente nas aulas e sem análise filosófica e histórica, podem ficar 
obsoletos no primeiro encontro com interesses capitalistas que o aluno tiver, ao sair da escola.

Por tudo o que expusemos, as inúmeras contribuições do ensino contextual a partir da História e Filosofia se fazem necessárias na prática docente na área de ensino de Ciências Naturais, para uma abordagem mais interessante e crítica do conhecimento científico. Como educador, segundo Matthews (1998), é necessário saber mais do que deve ser ensinado, deve-se conhecer sobre como esse conhecimento surgiu e quais são suas limitações, um saber sobre e da ciência.

Este trabalho surgiu da premência de debater a importância do ensino numa abordagem histórico-filosófica com as(os) docentes do Ensino Fundamental do município de São Mateus-ES, e apresentar propostas para a inserção da história da ciência na educação em ciências. O propósito da formação é que as(os) professores tenham condições de desenvolver aulas de ciências que revelem potencialidade para levantar debates sobre o desenvolvimento científico em suas dimensões humana, social, política, econômica, cultural, religiosa e ética, o que, segundo Praia (2012), constitui-se, hoje, um desafio para os educadores, implicando, não raras vezes, o abandono de uma série de certezas, crenças e valores.

\section{Metodologia}

O minicurso de que trata esse trabalho ${ }^{1}$, realizado junto a educadoras(es) de ciências do Ensino Fundamental (aberto também para outras áreas), teve como objetivos debater a importância do ensino de ciências numa abordagem histórico-filosófica e propor a inserção da história da ciência no ensino de ciências na educação básica.

O processo de formação foi organizado da seguinte forma:

1. Breve diagnóstico da abordagem de ensino adotada pelos participantes em sala de aula, através de um questionário inicial. O principal objetivo do

1 O minicurso foi apresentado no evento SEMFILI: Seminário Internacional de Educação, filosofias, infâncias: filosofar com infâncias, resistir na escola, ocorrido em São Mateus-ES, em agosto de 2018. 
questionamento consistiu em identificar se os (as) professores faziam uso da história e filosofia da ciência nas aulas. O questionário, segundo Gil (1999, p.128), pode ser definido "como a técnica de investigação composta por um número mais ou menos elevado de questões apresentadas por escrito às pessoas, tendo por objetivo o conhecimento de opiniões, crenças, sentimentos, interesses, expectativas, situações vivenciadas etc.".

2. Introdução teórica sobre aspectos históricos e filosóficos no desenvolvimento da ciência, segundo as ideias de Alfonso-Goldfarb (2004), norteados por abordagens fundamentadas em análise de documentos que focalizam interações de aspectos epistemológicos, historiográficos, sóciohistórico e culturais nos processos de elaboração, transmissão e transformação dos conceitos científicos. O objetivo desta etapa da formação foi refletir não só sobre as variâncias da própria história da ciência, mas também a noção de ciência em diferentes épocas (ALFONSO-GOLDFARB, 2008, p.7).

3. Preleção teórica sobre a importância da história e filosofia no ensino de ciências, defendendo um ensino que incorpore a real construção do conhecimento científico: a ciência como construção histórica e humana; a visão do conhecimento como aberto, que pode ser refutado, alterado e que não é uma verdade absoluta, pronta, estática, segundo Nascimento (2016). Uma abordagem de educação em ciências em contraponto ao que vemos na maioria das escolas: ensino positivista que evidencia a fragmentação dos conhecimentos, na especialização, na superioridade das ciências exatas sobre as humanas; na ciência como forma de conhecimento objetivo, passível de verificação rigorosa e inalterável; nos ideários ilusórios: "a descoberta" e "o gênio”.

4. Apresentação teórica de uma análise crítica da história da ciência comumente presente nos livros didáticos, considerando as questões apresentadas por Carneiro e Gastal (2005) que apontam uma história da ciência abordada de modo linear, consensual, anedótica e ausente de contexto histórico amplo.

5. Apresentação e debate sobre duas propostas de ensino de ciências utilizando o ensino contextual a partir da abordagem histórico-filosófica: 
5.1. A história de Gregor Mendel e sua contribuição para a genética. A proposta teve como objetivo desmitificar a ideia de gênio; perceber a ampla formação de Mendel; analisar sua pesquisa com ervilha (publicada) e outras espécies (não publicada) e evidenciar a existência de conhecimentos prévios usados por Mendel (BRANDÃO e FERREIRA, 2009).

5.2. Os estudos de Joseph Priestley sobre os diversos tipos de "ares" e os seres vivos. A proposta objetivou apresentar um conceito a respeito da natureza da ciência e da pesquisa e sua íntima relação entre química, medicina e história natural; as influências de ideias preconcebidas na pesquisa, as dificuldades que surgem ao se tentar compreender fatos novos e inesperados; as diferenças entre as interpretações do próprio Priestley e as aceitas hoje em dia; as contribuições de diversos pesquisadores e não apenas um solitário cientista e o contexto mais amplo em que se situavam os experimentos descritos de forma tão simplista pelos livros didáticos (MARTINS, 2009).

6. Um breve diagnóstico da percepção dos participantes acerca do minicurso, através de um questionário. O principal objetivo deste questionário foi identificar se os participantes mudaram suas percepções acerca do uso da história e filosofia da ciência, enfatizando a possibilidade do ensino de ciências a partir dessa abordagem.

\section{Resultados e discussão}

Ao todo tivemos 22 participantes no minicurso, sendo a maioria formada em pedagogia, contemplando também professores formados em cursos de licenciatura em ciências biológicas, química, matemática, letras, engenharia agronômica e história.

Quando perguntados se já haviam abordado a história e filosofia de ciências nas aulas, mais de $50 \%$ dos participantes dizem ter realizado o ensino a partir dessa abordagem. Contudo, nem todos (as) parecem compreender o que de fato é a história e filosofia da ciência quando, ao responder a pergunta "como foi realizada a abordagem?", disseram: "no processo de formação das plantas", "estudando plantas e animais", "explicando a história evolutiva dos animais, a formação do planeta terra". O conteúdo de plantas e animais, na educação 
básica é apresentado no livro didático organizado a partir das relações filogenéticas, ou seja, a partir da história evolutiva dos diferentes organismos. A evolução é uma teoria basilar das ciências biológicas, usada para organizar o conteúdo de biologia no livro didático, e também apresentando-se, ela mesma, enquanto um conteúdo a ser trabalhado. Por estarem todos os organismos vivos relacionados uns aos outros com maior ou menor grau de proximidade filogenética, a história evolutiva dos diferentes grupos de organismos é utilizada para organizar o conteúdo de biologia animal e vegetal. Assim, os organismos mais próximos evolutivamente, ou seja, na história do surgimento dos diferentes grupos de organismos, estão também mais próximos na organização do livro didático.

Neste sentido, percebemos que o ensino contextual a partir da história e filosofia da ciência não é compreendido por alguns professores, que o confunde com conteúdos a serem lecionados, como no caso exposto acima, em que os professores confundiram os conteúdos de história evolutiva, evolução e história da formação da terra e do surgimento da vida com história e filosofia da ciência. O ensino contextual foi também confundido com outras abordagens, como pode ser confirmado pela fala de outro professor que disse que ao "fazer um diagnóstico do tema abordado, trabalhando especificidade para criar um sentimento de pertença" estaria utilizando-se da história e filosofia da ciência no ensino. Esta proposta, adotada por este professor, não se relaciona ao ensino contextual histórico-filosófico, ainda que apresente uma perspectiva crítica de educação (ROCHA e SILVA, 2013).

Quando questionados de que forma realizam a abordagem histórico filosófica no ensino, alguns professores disseram que isso se dá a partir do uso de recursos didáticos variados como textos, filmes e vídeos. Os professores não explicaram de que forma utilizam tais recursos, ainda que eles possam de fato serem utilizados na abordagem histórico-filosófica quando trazem o exame da vida e da época de pesquisadores individuais e humaniza a matéria científica, tornando-a menos abstrata e mais interessante aos alunos (PRESTES e CALDEIRA, 2009). 
Ainda em relação à pergunta anterior, houve algumas respostas apontando o uso de experimentos e aulas práticas como forma de abordagem histórico-filosófica do ensino. Ainda que os professores, novamente, não tenham apresentado de que forma realizam o uso desses recurso e modalidade didáticos, podemos depreender que tal estratégia aproxima-se do ensino investigativo (CARVALHO, 2014) e não se relaciona diretamente com a abordagem histórico-filosófica. A experimentação, frequentemente realizada nas aulas práticas, propicia a passagem da ação manipulativa para a ação intelectual, o trabalho em grupo e a solução de problemas, elementos presentes e necessários ao ensino investigativo (CARVALHO, 2014). Neste sentido, o uso das aulas práticas e da experimentação não necessariamente se relaciona ao ensino contextual a partir da história e filosofia da ciência.

Apenas três professores apontaram, de maneira clara, o ensino contextual das ciências em suas aulas ou se aproximaram disso. Essa abordagem ficou evidente na fala da professora que disse "pesquiso com os alunos o histórico do assunto a ser abordado", evidenciando que a professora trabalha em suas aulas a perspectiva histórica do conhecimento. Outra professora demonstrou realizar o ensino contextual histórico-filosófico a partir do debate de avanços tecnológicos que permitiram o desenvolvimento do conhecimento científico, ao falar que discute com seus alunos a "importância do microscópio para o ensino e a pesquisa".

Por fim, dois professores não responderam a pergunta e $30 \%$ deles disseram não realizar a abordagem histórico-filosófica no ensino. Como justificativa, estes professores apontaram o desconhecimento dessa abordagem, a ausência de formação específica sobre essa metodologia (na formação inicial) e o fato de trabalharem nos anos iniciais do ensino fundamental. Essas justificativas evidenciam uma lacuna na formação desses educadores a qual, segundo Auler (2002), deve se concretizar na perspectiva de associar ao ensino de conceitos científicos a problematização destas construções, propiciar a compreensão do entorno da atividade científico-tecnológica na avaliação dos impactos pós-produção, bem como na definição de parâmetros em relação ao desenvolvimento científico-tecnológico. Isso traz criticidade em relação à ciência 
contribuindo para a percepção de que ela não é neutra ou desprovida de intencionalidades e, sim, influenciada por aspectos culturais, sociais, econômicos e políticos contemporâneos à sua elaboração.

Diante do exposto podemos perceber que, ainda que os professores digam realizar o ensino contextual a partir da história e filosofia da ciência, poucos de fato utilizam essa abordagem. A ausência desse conteúdo na formação inicial dos professores, ou mesmo em atividades de formação continuada aparentemente favorece a ausência do ensino contextual das ciências. Essa ausência é grave, pois permite a manutenção da visão deformada da ciência quando, dentre outros fatores, mantém a existência de uma concepção de ciência individualista, elitista, empiro-indutivista, ateórica, linear, cumulativa e ahistórica, frequentemente presentes no ensino tradicional que não problematiza a construção do conhecimento científico (CACHAPUZ et al., 2011).

Após a realização do minicurso, a partir do questionário aplicado, observamos que todos as/os professoras/es consideram importante o ensino contextual histórico-filosófico e responderam dizendo que irão incorporá-lo às suas aulas. A maioria dos professores apontaram que essa incorporação se dará a partir da pesquisa sobre a história do conhecimento a ser trabalhado. Também houve respostas ligadas às limitações do livro didático para auxiliar nesse ensino contextual, quando o professor diz "não confiar só no livro didático", ou "fazendo pesquisas além do livro didático". Isso evidencia que, após os conteúdos trabalhados no minicurso, os professores têm clareza da necessidade de analisar criticamente e/ou buscar outras fontes para permitir "ao aluno conhecer sua verdadeira história [das ciências], sua evolução que vai além do que está no livro didático".

Um aspecto muito importante que apareceu, explicitamente, em algumas falas foi o entendimento, pós minicurso, do que de fato é o ensino contextual a partir da história e filosofia da ciência. Isso está presente quando os professores dizem que vão "investigar de que forma o cientista chegou na teoria", "mostrar aos alunos o processo e a evolução da ciência", "abordar a desconstrução da ciência enquanto inquestionável". Essas falas evidenciam que os professores mudaram sua concepção, passando ao entendimento do que é a abordagem de 
ensino a partir da história e filosofia da ciência, não mais confundindo-a com a teoria evolutiva.

\section{Considerações finais}

A partir do nosso minicurso, que teve duração de apenas 2 horas, já observamos uma mudança conceitual concreta por parte dos participantes que irá, inevitavelmente, influenciar em sua prática docente. A realização de nosso minicurso vai ao encontro do que Cachapuz et al. (2000) defendem, que deve haver uma filosofia de formação de professores, de exigência continuada, que permita a condução a mudanças de perspectivas e, consequentemente, a novas práticas inovadoras pelas atitudes e valores que introduzem a uma outra cultura de educação científica. A necessária renovação do ensino de ciências, discutida por Cachapuz et al. (2011), requer também uma renovação da formação docente, que dialogue com uma educação científica crítica, a qual será inatingível se continuarmos com o ensino hegemônico tradicional e acrítico.

Neste sentido e em função dos aspectos discutidos neste artigo, observamos a importância do minicurso ministrado e, sobretudo, a importância da formação inicial e/ou continuada em ensino contextual a partir da história e filosofia da ciência. É de fundamental relevância haver outras oportunidades de formação de docentes que trate de aspectos históricos e filosóficos da ciência, sendo este um tema que necessita de maior atenção na formação de professores.

\section{Referências bibliográficas}

ALFONSO-GOLDFARB, Ana Maria. O que é História da Ciência? São Paulo: Brasiliense, 2004.

ALFONSO-GOLDFARB, Ana Maria. Centenário Simão Mathias: Documentos, Métodos e Identidade da História da Ciência. Circumscribere: International Journal for the History of Science. [SI], v. 4, p.1-4, maio de 2008. ISSN 19807651.Disponível em: <https://revistas.pucsp.br/circumhc/article/view/678/921>. Data de acesso: 28 out. 2019.

AULER, Décio. Interações entre ciência-tecnologia-sociedade no contexto da formação de professores de ciências. Tese apresentada ao Programa de Pós-Graduação em Educação da Universidade Federal de Santa Catarina. Florianópolis: UFSC, 2002. 
BRANDÃO, Gilberto Oliveira; FERREIRA, Louise Brandes Moura. O ensino de Genética no nível médio: a importância da contextualização histórica dos experimentos de Mendel para o raciocínio sobre os mecanismos da hereditariedade. Filosofia e História da Biologia, v. 4, p. 43-63, 2009.

CACHAPUZ et al. Uma visão sobre o ensino das ciências no pós-mudança conceptual. Inovação, 13, 2-3, 2000.

CACHAPUZ, António et al. A necessária renovação do ensino das ciências. São Paulo: Cortez, 2011.

CARNEIRO, Maria Helena da Silva; GASTAL, Maria Luiza. História e filosofia das ciências no ensino de biologia. Ciência \& Educação, v. 11, n. 1, p. 33-39, 2005.

CARVALHO, Ana Maria Pessoa de. O ensino de ciências e a proposição de sequências de ensino investigativas. In: CARVALHO, Ana Maria Pessoa (Org.). Ensino de ciências por investigação: condições para implementação em sala de aula. São Paulo: Cengage Learning, 2014.

CHASSOT, Attico. Alfabetização científica: questões e desafios para a Educação. 4 ed. ljuí: Editora Unijuí, 2006.

CHASSOT, Attico. A ciência através dos tempos. São Paulo: Moderna, $20^{a}$ Edição, 2008.

CHASSOT, Attico. Educação consciência. $2^{a}$ ed. Santa Cruz do Sul: Ed. UNISC. 2007a.

GIL, Antônio Carlos. Métodos e técnicas de pesquisa social. 5. ed. São Paulo: Atlas, 1999.

LIPMAN, M. O Pensar na Educação. Petrópolis, Rio de Janeiro: Vozes, 1995.

MARTINS, Roberto de Andrade. Os estudos de Joseph Priestley sobre os diversos tipos de "ares" e os seres vivos . Filosofia e História da Biologia, v. 4, p. 167-208, 2009.

MATTHEWS, M. R.: 1988, A Role for History and Philosophy in Science , Teaching', Educational Philosophy and Theory 20(2), 67-81.

NASCIMENTO, Viviane Briccia. A natureza do conhecimento científico e o ensino de ciências. In: CARVALHO, Ana Maria Pessoa, et al (Org.). Ensino de Ciências: unindo a pesquisa e a prática. São Paulo: Cengage Learning, 2016. cap. 3.

PRAIA, João Félix. Contributo para uma leitura possível de um percurso profissional. Em: $O$ ensino das ciências como compromisso científico e social: os caminhos que percorremos. CACHAPUZ, A. F.; CARVALHO, A, M. P. de; GIL-PÉREZ, D. (orgs.). São Paulo: Cortez, 2012. 
PRESTES, Maria Elice Brzezinski; CALDEIRA, Ana Maria de Andrade. A importância da história da ciência na educação científica. Filosofia e História da Biologia. v. 4, p. 1-16, 2009.

ROCHA, André Luis Franco da; SILVA, Antonio Fernando Gouvêa da. Para que ensinamos zoologia na escola: Construindo uma possibilidade prática. In: DUSO, Leandro; HOFFMAN, Marilisia Bialvo, (Ogr.). Docência em ciências e biologia: propostas para um continuado (re)iniciar. ljuí: Unijuí, 2013. cap. 5.

\section{Sobre os Autores}

Dalana Campos Muscardi

dmuscardi@gmail.com

Doutora em Entomologia (UFV, 2013). Professora do Curso de Licenciatura em Educação do Campo da Universidade Federal do Espírito Santo/Campus São Mateus.

\section{Débora Schmitt Kavalek}

quimicadebora@hotmail.com

Doutora em Educação em Ciências (UFRGS, 2016). Professora da Universidade Federal do Sul da Bahia, Instituto de Humanidades, Artes e Ciências, Campus Paulo Freire. 